\title{
The Role of Diagnostics of the Enterprise Anti- crisis Management in Ensuring Economic Security of Regions
}

\author{
Alexander Rodionov \\ Department of Natural Sciences, Information Technology and \\ Management \\ Kamensk Institute (branch) of FSBEI HE "South Russian State \\ Polytechnic University (NPI) named after M.I. Platov, \\ Kamensk, Russia \\ av.box@bk.ru \\ Natalia Khyzhak \\ Department of Economics and Finance \\ Humanitarian and pedagogical Academy (branch) \\ V. I. Vernadsky Crimean Federal University \\ Yalta, Russia \\ shamnp75@gmail.com
}

Abstract-The article substantiates the influence of the enterprise anti-crisis management on the level of economic security of the regions; the issues of the necessity to assess the anti-crisis management of the enterprise are considered; criteria for assessment of anti-crisis management by a number of parameters are proposed; effectiveness analysis of the proposed criteria is carried out. It is proved that the scope of regulatory measures and mechanisms to ensure the economic security of the region are: the development of the regional market of goods and services, inter-regional relations; ensuring the effective functioning of the regional labor market; effective fiscal policies in the region; development of industrial and social infrastructure; the use of natural resources and environmental protection; the power supply in the area; an information security management activities of public authorities and economic entities, and transparency of management. Many financial indicators are criteria or standards or limits at the same time: for example, the level of return, and the funds of various financial institutions are an indicator of the standard or limit. Thus, these mobile elements of the financial mechanism are closely intertwined, interconnected and interact in the planning and forecasting of financial markets. Indicators for diagnosing the state of anti-crisis management of the environment were identified as a result of studying the factors of influence of the external environment on the enterprise, the results of practical activities of enterprises, and the analysis of literature sources on the subject under study. The relationship between production and marketing solutions occupies a significant place in the process of implementing anti-crisis management, since it takes into account the interests of counterparties that interact with the enterprise.

Keywords-economic security of the region, sustainability of environmental development, anti-crisis management, management assessment criteria, marketing efficiency, global interest of the enterprise.

\author{
Diana Mardar \\ Department of Economics and Finance \\ Humanitarian and pedagogical Academy (branch) \\ V. I. Vernadsky Crimean Federal University \\ Yalta, Russia \\ dianam08@inbox.ru
}

\section{INTRODUCTION}

The problem of ensuring economic security of regions is relevant from the standpoint of achieving their stable and balanced strategic development. As practice shows, economic security is a multi-level structure that depends on the efficiency of interaction at all its levels: state, regional, branch, economic sector and enterprise. The system of external and internal support and environment of the enterprise is dynamic and unstable. It constantly changes its conditions and forms of existence. This can affect the sustainability and performance of the enterprise in different ways. In this regard, it is advisable to have a system of early diagnostics and notification of crisis phenomena for the enterprise. The system can be simple, based on several indicators, but must provide the chief executive with warning information about the current state.

In its turn, if the enterprise cannot rely upon sustainable development and support from the external environment, then its growth and changes will be slow, and the result of its activities will be extremely insignificant. In this regard, the issues of determining the level of anti-crisis management at the enterprise are very relevant.

The problem of economic security of a region and enterprise at different levels of the hierarchy of economic management, is studied in scientific works of such outstanding domestic and foreign scientists as L. Abalkin, V. Abramov, Yu. Altukhov, V. Andreychuk, G. Androshchuk, O. Baranovsky, I. Binko, V. Bogomolov, Z. Varnaliy, G. Vechkanov, O. Vlasyuk, V. Vorotin, A. Galnitsky, T. Gladchenko, O. Goncharenko, A. Gorbunov, V. Dukhov, A. Draga, M. Ermoshenko , A. Kachinsky, V. Kirilenko, T. Klebanova, T. Kovalchuk, A. Kozachenko, B. Kravchenko, P. Krainev, D. Lyapin, I. Mazur, O. Malinovskaya, V. 
Muntiyan, G. Pasternak, N. Reverchuk, V. Senchagov, A. Sukhorukov, T. Khailova, V. Shlemko and others. However, insufficient attention is paid to the study of the importance of enterprise anti-crisis management assessment in the system of economic security of regions.

\section{METHODS}

General scientific methods of analysis and synthesis were used as research tools, as well as specific research methods such as: monographic method, abstract-logical, etc.

\section{MAIN PART}

At the present stage of domestic economy development, the level of anti-crisis management of the enterprise environment can be characterized as very low, not meeting the established criteria. In this regard, a need arises to create special organizational mechanisms for managing anti-crisis measures at enterprises, as an element of a high-quality management system for the economic security of the region. One of the important tasks is creation of the system of indicators that provide a complete description of new mechanisms for the formation and development of relations at enterprises, in the context of the region strategic development.

Assessment of the anti-crisis management of the environment can be carried out by examining a number of the following aspects.

First, the form of manifestation and steps towards the formation of anti-crisis management of the enterprise are analyzed, general style of management and the state of the enterprise, methods of managing the environment are characterizing.

Second, the sustainability of the environment development is disclosed in such substantial characteristics as methods of enterprise management, management structure, manpower policy, social policy.

Third, the sustainability of the environment development is characterized by the level of development of office administration and external communications of the enterprise, including the culture of public relations; culture of relationship with business partners, clients, banks, government agencies, etc.

The most important element of the state's economy organization, which forms stable spatial ties and ensures the integrity of economic and social development, is the territorial structure. It is the result of the development and distribution of productive forces and an important prerequisite for the further development of both the economy as a whole and ensuring the country's economic security.

Economic security of the region is the ability of the regional economy to function in the mode of extended reproduction, that is, to show sustainable economic growth, to deliver maximum acceptable living conditions and personal development for the majority of the population. According to the process approach, economic security management is a continuous interconnected sequence of actions (management functions of different levels) aimed at ensuring economic security. The main functions of economic security management include the formation of development goals of the subject to management and the development of a strategy to achieve them (program of action). The following types of strategies for ensuring economic security should be distinguished, in particular those that are aimed at: preventing the transformation of destabilization factors into a security threat; termination of existing threats; restoration of the safe state of objects (compensation for losses). The first and second types of strategies are focused on the prevention of threats and counteraction (preference is given to them), the last - on compensation of damage to objects of economic security by actions and appropriate mechanisms.

The quality of the economic security management system for a region is ensured by the efficiency of making managerial decisions that take into account the system of mutual economic interests of both economic entities and regional authorities. The function of economic security management on the part of the state is largely determined by regulation, it is considered as a focused influence of the authorities on the main economic parameters to achieve a balance - sustainable development of the economy and the interests of business entities and society, as well as a package of management actions to neutralize the identified threats and leave the hazard area. Regulatory measures and mechanisms are developed simultaneously with the forecasts of socioeconomic development, implemented in a program for ensuring economic security and sustainable development of security objects [1].

The sphere of application of regulatory measures and mechanisms to ensure the economic security of the region are: development of the regional market of goods and services, interregional ties; ensuring the effective functioning of the regional labor market; implementation of an effective budgetary policy in the region; development of industrial and social infrastructure; use of natural resources and environmental protection; energy supply of the region; information support for the management activities of authorities and business entities, transparency of the administrating authorities activities.

There can be several lines of research for crisis events.

In consolidated budgeting, mainly average rates and standards are used, in planning the financial results of specific economic agencies - individual ones.

Financial norms and standards are also subdivided into approved and calculated ones. The approved ones are established by the current legislation, the calculated ones are used in internal planning. The approved ones include tax rates, rates of social contributions to off-budget funds; to the calculated ones - the checkoff rates and standards for the formation of accumulation and consumption funds of enterprises and organizations, the renewal fund of fixed assets and others that regulate the financial activities of enterprises and institutions.

There are also differences between uniform norms and standards, for example, depreciation rates for different economic facilities and industries, and differentiated - norms and standards for working capital, which are not the same for different business entities.

Many financial figures are at the same time norms, standards or limits: for example, profitability level, the name of different financial funds are both an indicator and a standard or limit. Thus, there is a close interlacing, interconnection and interaction of these moving elements of 
the financial mechanism in planning and forecasting financial results of economic activity.

For the purpose of prompt identification of crisis events in the financial, production, social and personnel activities of the enterprise, an automated diagnostic system is proposed. Its database is data from the automated accounting of the enterprise performance - programs like $1 \mathrm{C}$, personnel records, etc.

Indicators for diagnosing the state of environment anticrisis management were identified as the result of the study of external environment factors influencing the enterprise, the results of practical activities of enterprises, analysis of literature on the topic under study.

The state of the level of anti-crisis management is determined by the state of its types as subsystems, which can be described by a number of parameters in the form of indicators [2]. In addition to the analysis of structural elements, it is necessary to consider summarizing and specific indicators that characterize the effect of innovation on the dynamics of changes and the sustainability of the environment development. It is advisable to carry out the evaluation on an annual basis, or every six months. In case of a more detailed analysis, diagnostics can be carried out more often. While developing the method for diagnosing the level of anti-crisis management of the enterprise, it is necessary to take into account that the indicators are formed according to groups of anti-crisis management, which determines equal significance of the diagnostic groups of the enterprise defined in the study. It was proved [1] that to check the effectiveness and efficiency of the assessment method, it is sufficient to use at least four indicators. The assessment of the level of anticrisis management at the enterprise according to the selected indicators is carried out by its specialists. At the same time, the involvement of specialists and experts from outside organizations can provide a higher objectivity.

Either internal or external experts should conduct a qualitative assessment. Evaluation is carried out according to Likert scale [4] with the assignment of points from 0 to 5 points. The lowest level is 0 , the highest level is 5 points. The result of the expert assessment is the average for the entire group within the range of $0-5$ points. According to the results of the assessment, the experts deduce the average indicator for groups of indicators within the assessment from 0 to 5 points, as well as in a relative system to establish the most significant and dominant type of anti-crisis management of the enterprise environment. Final results of diagnostics of the state of anti-crisis management of the enterprise environment are expressed by the summarizing index "Anti-crisis management" (Ia), which can be calculated using the following formula:

$$
\mathrm{K}_{\mathrm{a}}=\frac{\sum_{1}^{3} \mathrm{O}_{\phi \mathrm{H}}}{\sum_{1}^{3 \Sigma^{2} \mathrm{O}_{\max }}}
$$

where $A_{\text {asa }}$ - activity-specific actual assessment;

$A_{\max }$ - activity-specific maximum assessment.

Marketing orientation of management, as well as the marketing orientation of production, is important and significant for making anti-crisis decisions in the process of reproduction of capital, and allows, to a certain extent, to take into account the interests of the subjects of the external environment interacting with the enterprise. The results of marketing research to a large extent should be the basis for investment decisions, which places high demands on them in terms of their effectiveness. This is due, on the one hand, to the fact that their results are the basis for making and further implementation of management decisions in the field of extended reproduction of capital as production and technical facilities to increase the degree of compliance with the global interest of the enterprise - increasing sales. On the other hand, the package of the enterprise marketing decisions - marketing strategy - is a significant investment project.

Effectiveness of marketing reflects the effectiveness of the anti-crisis model of behavior in the market chosen by the enterprise. Quantitative assessment of the effectiveness of marketing (EMR) can be done using the indicator of the market return of enterprise assets, determined as follows:

$$
\mathrm{E}_{\mathrm{MR}}=\mathrm{SV}: \mathrm{E}_{\mathrm{AV}},
$$

where $E_{A V}$ - enterprise assets value;

$S V$ - sales volume.

Marketing effectiveness along with production efficiency determines the amount of profit of the enterprise, which is an integral part of income. Enterprise profit on advanced capital $\left(\mathrm{P}_{\mathrm{AC}}\right)$ can be defined as the product of production efficiency and marketing efficiency indicators:

$$
\mathrm{P}_{\mathrm{AC}}=\mathrm{E}_{\mathrm{PR}} \times \mathrm{E}_{\mathrm{MR}},
$$

where $E_{P R}-$ is production efficiency.

Quantitatively, the production efficiency in general can be determined as the share of the enterprise profit in the total sales from the sale of products (works, services), using for this the profitability index of sold products, which is calculated using the following formula:

$$
\mathrm{E}_{\mathrm{PR}}=\mathrm{E}_{\mathrm{RB}} / \mathrm{SV} \text {, }
$$

where $-E_{R B}$ - earnings retained in the business.

The role of the two components of the effective use of enterprise assets - production efficiency and marketing effectiveness - depends on the stability of the economic situation in the country, region, on the stage of the product and enterprise life cycle and on the type of products. So, for example, enterprises that are at the first or second stage of their life cycle, or producing new products, as a rule, carry out aggressive marketing policy in order to increase the volume of sales of their products. In this case, the growth of the $P_{A C}$ indicator is provided mainly due to the effectiveness of marketing. In the process of mastering its niche in the market by the enterprise, the growth or stability of the $P_{A C}$ indicator largely depends on the production efficiency.

Thus, based on the position of compliance with the global interest of the enterprise, the amount of investment in extended reproduction depends on the level of compliance with the global interest that determines the market position of the enterprise and on the need and possibility to increase this level.

At the same time, it is not enough just to acknowledge the unsatisfactory degree of compliance with the global interest 
of the enterprise. Simultaneously, the possibility of increasing the degree of compliance with the global interest and functional interests of the enterprise should be determined. An increase in the degree of observance of the global interest and associated functional interests of the enterprise is due, on the one hand, to the internal capabilities of the enterprise, and, on the other hand, to its coordination with the interests of the subjects of the external environment of the region. At the same time, the interests of the subjects of the external environment can be counter or multidirectional and unidirectional. The partners of the enterprise are among the subjects of the external environment, whose interests are of a reciprocal nature. Unidirectional nature is inherent in enterprises - competitors with the same or similar interests.

The amount of profit required to ensure the anti-crisis development of the enterprise is determined by the degree of compliance with the global interest of the enterprise [5]. Since the enterprise seeks to increase profits, it becomes necessary to study issues related to the degree of observance of the interests of the enterprise, and their coordination with the interests of the subjects of the external environment of the region. Let's consider the proposed approaches to solving such issues.

In the most general form, it is possible to give quantitative assessment to the degree of compliance with a particular interest of the enterprise by comparing the indicators characterizing the interests of the enterprise and the indicators achieved in the field of the enterprise activities. Based on these results, we can judge the degree of compliance with the interests of the enterprise, draw appropriate conclusions and build a system to protect its interests. The assessment of the degree of observance of the global interest of the enterprise, which determines the position of the enterprise in the market, should be carried out taking into account the free market capacity for the corresponding products, works or services [7]. Moreover, depending on the type of product (work or service), the determination of the degree of observance of the global interest can be carried out as for the national, regional or local market. The degree of observance of the global interest of the enterprise (IC) is proposed to be evaluated based on the results of comparison of such indicators as the free market capacity for a particular product and the production capacity of the enterprise $\left(P_{C i}\right)$. Formally, such a comparison has the following form

$$
I C=\left(E_{p i}-\sum_{j=1}^{n} Д_{j}\right) / \Pi_{\mathrm{M}_{i}} \times K_{p o},
$$

where $i$-index of product (works or services);

$j$ - competitor index;

$n$ - number of competitors;

$C_{m i}$ - market capacity;

$M S h_{j}$ - market share that is controlled by competitors;

$F_{p o}$ - adjustment factor of the production capacity of the enterprise, which takes into account resource limitations

The results of such a comparison can be as follows: $I C=1$, $I C>1, I C<1$.

The comparison of results in the first and second cases indicate full compliance with the global interest of the enterprise, i.e. free market capacity is equal to or exceeds the existing production capabilities of the enterprise, represented in the calculating formula (5) by the indicator of production capacity. The result of comparing the free market capacity and the production capacity of the enterprise, close to 1 , is most likely possible only theoretically. Nevertheless, in practice, such a result can be obtained by assessing the global interest of monopoly enterprises. Full or close to the full observance of the global interest of the enterprise (IC $\geq 1$ ) significantly weakens the dependence of the enterprise market position on the volume, dynamics and depth of the processes of expanded capital reproduction, which probably explains the lack of significant interest of enterprises of such class in investing in this direction.

With full satisfaction of the global interest of the enterprise, the amount of investment required to ensure the expanded reproduction of the enterprise's capital is determined based on the amount of funds required to replace the physically worn out means of production and to maintain the existing sales volume and quality of products (works or services) [8]. In this case, the amount of investments required to ensure the enterprise stable development and the implementation of the enterprise anti-crisis policy will not differ significantly from the investments which have already been made by the enterprise.

The source of economic security of the enterprise is its profit, i.e. the enterprise is economically secure if its activities are profitable. The level of economic security depends on the fact whether the enterprise has at its disposal its own profit in the amount sufficient to support the requirements of the economic security of the enterprise [9].

Such a conclusion entails the need to analyze both the absolute and the relative profit of the enterprise, by comparing the amount of profit obtained as a result of using the assets of the enterprise.

The economic security management system is a rather complex set of elements that implements the basic principles and management functions, which is capable of ensuring the acceptable state of economic security, has properties for adaptation and continuous improvement, taking into account changes in the internal and external environment.

The most effective method of managing economic security is a result-oriented program that implements an integrated approach and is a system of specific forms and methods of management aimed at implementation of complex programs; a set of techniques that make it possible to present the solution of the problem as a hierarchy of goals defined by the levels of affinity, significance and expediency, with their subsequent achievement through the implementation of the system of interrelated activities [10].

Current practice shows that the construction of a target model for managing the economic security of a region is the most important and complex element of methodological work on the implementation of the result-oriented management method.

Therefore, in order to achieve the maximum effect of result-oriented management, it is necessary to ensure the completeness of the integrated target program of economic security of the region, for doing this its development and implementation should include the following stages [11]: 
1. Identification of a problem situation in the region and the formulation of a specific problem.

2. The choice of a problem situation is solved on program base: determination of the desired state of the object of economic security (not assessed as threatening) identification and assessment of the acting factors of destabilization; determination and assessment of expected losses from identified threats; assessment of threats in accordance with their importance, time of the onset, and so on; making a decision on the choice of a problem situation.

3. Formation of program goals and objectives (hierarchy of goals).

4. Preliminary determination of the necessary resource provision for solving the problem situation, setting of limits on the types of resources.

5. Development of a strategy for ensuring economic security as a set of measures - techniques, methods, instruments to achieve program goals.

6. Redetermination of the available resources provision for the implementation of the chosen strategy and its distribution by types of activities and time.

7. Preparation of a draft target program and its coordination with ongoing ones.

8. Program authorization, communicating to the performers.

9. Establishing of organizational mechanism for managing the target program.

The analysis of target models of the regions showed that the most significant is the achievement of the following subgoals (solving problems): increasing the effectiveness of economic activities of all business entities, regardless of the form of ownership and type of activity; increasing budget revenue of the regional budget [12]. Enhancement of economic activity effectiveness is a sub-goal of various components of the economic security strategy (industrial, agro-industrial, investment policy) and a consequence of the implementation of others (development of market, industrial infrastructure, etc.), but at the same time it affects the successful implementation of most components of the economic security strategy. Consequently, the increase of the effectiveness of economic activity, reproduction and stabilization of production is the main goal of the strategy for ensuring economic security of most regions of the country.

Each level of economic security management should form favorable conditions and prerequisites for security and stability of components and functional components of a lower-level economic security object. Such conclusions are confirmed in the study of T. Gladchenko [3], who substantiates not only the expediency of dividing such levels of economic security as state, regional, sectoral, enterprises, but also considers it to be an objective prerequisite for the development of the definition of "economic security".

\section{CONCLUSION}

As the result of the study, approaches to the assessment of the anti-crisis management of the enterprise environment were established and a number of indicators that allow to carry out a quantitative assessment of the level of the proposed measures were identified. Of course, the assessment methods proposed cannot fully assess the entire variety of interaction between the enterprise environment and the results of its activities, which leaves room for further research. There is also an interconnection between the development of the enterprise and such functional aspects of the security of the region as: financial, social, technological, food, external economic, demographic, energy and environmental. The interaction of regional authorities and economic entities in the system of program-targeted management of economic security should be based on the use of a set of economic regulators of economic activity related to the economic interests of economic entities of the region.

\section{REFERENCES}

[1] E.M. Korotkov, Anti-crisis management: Handbook, Moscow, 2005, $620 \mathrm{p}$.

[2] Yu.A. Arutyunov, Anti-crisis management, Moscow, 2013, 416 p.

[3] T. N. Gladchenko, "Scientific and methodological basis of the mechanism of public administration and regulation of the security system of entrepreneurial activity: regional aspect: Abstract of thesis for a Candidate Degree in state administration": 25.00.02 "Mechanisms of public administration", Donetsk, 2004, 20 p.

[4] Naresh K. Malhotra, Marketing Research. A practical guide. Translation from English, Moscow, 2002, 960 p.

[5] L. S. Sytnik, Organizational and economic mechanism of anti-crisis management of the enterprise, Donetsk: IIE NAS of Ukraine, 2000. $503 \mathrm{p}$.

[6] H.E. Lee, Sustainable Economic Development. Resources, Environment and Institutions. Scarcity, Security, and Sustainable Development, 2015. P. 49-66.

[7] K.M. Murphy, R.H. Topel, "Some Basic Economics of National Security", American Economic Review, vol. 103 (3), 2013, pp. 508511.

[8] D.J. Lacombe, S.G. McIntyre, Hierarchical Spatial Econometric Models in Regional Science. In: Regional Research Frontiers. Vol. 2. Methodological Advances, Regional Systems Modeling and Open Sciences. Springer, 2017, pp. 151-167.

[9] D.S. Rickman, Regional Science Research and the Practice of Regional Economic Forecasting: Less Is Not More". In: Regional Research Frontiers. Vol. 1. Advances in Spatial Science. Springer, 2017, pp. 135-149.

[10] S.G. Svetun'kov, A.V. Zagranovskaya, I.S. Svetun'kov, Complexvalued analysis and modeling the uneven socio-economic development of Russian regions, St. Petersburg, 2012, 129 p.

[11] R. I. Malikov, K. E Grishin, Enabling institutional configuration of business environment as a factor of entrepreneurial capacity of a region. In: Reproductive potential of the region: Problems of quantitative measurements of its structural elements, Ufa, 2016, pp. 18-24.

[12] A.N. Ryakhovskaya, S.E. Kovan, Crisis management as a basis of creating a mechanism of sustainable business development: a monograph, Moscow, 2016, 169 p. 